\title{
Graded Exposure for Chronic Low Back Pain in Older Adults: A Pilot Study
}

Citation for published version (APA):

Leonhardt, C., Kuss, K., Becker, A., Basler, H-D., de Jong, J., Flatau, B., Laekeman, M., Mattenklodt, P., Schuler, M., Vlaeyen, J., \& Quint, S. (2017). Graded Exposure for Chronic Low Back Pain in Older Adults: A Pilot Study. Journal of geriatric physical therapy, 40(1), 51-59.

https://doi.org/10.1519/JPT.0000000000000083

Document status and date:

Published: 01/01/2017

DOI:

10.1519/JPT.0000000000000083

Document Version:

Publisher's PDF, also known as Version of record

Document license:

Taverne

Please check the document version of this publication:

- A submitted manuscript is the version of the article upon submission and before peer-review. There can be important differences between the submitted version and the official published version of record.

People interested in the research are advised to contact the author for the final version of the publication, or visit the DOI to the publisher's website.

- The final author version and the galley proof are versions of the publication after peer review.

- The final published version features the final layout of the paper including the volume, issue and page numbers.

Link to publication

\footnotetext{
General rights rights.

- You may freely distribute the URL identifying the publication in the public portal. please follow below link for the End User Agreement:

www.umlib.nl/taverne-license

Take down policy

If you believe that this document breaches copyright please contact us at:

repository@maastrichtuniversity.nl

providing details and we will investigate your claim.
}

Copyright and moral rights for the publications made accessible in the public portal are retained by the authors and/or other copyright owners and it is a condition of accessing publications that users recognise and abide by the legal requirements associated with these

- Users may download and print one copy of any publication from the public portal for the purpose of private study or research.

- You may not further distribute the material or use it for any profit-making activity or commercial gain

If the publication is distributed under the terms of Article $25 \mathrm{fa}$ of the Dutch Copyright Act, indicated by the "Taverne" license above, 


\title{
Graded Exposure for Chronic Low Back Pain in Older Adults: A Pilot Study
}

\author{
Corinna Leonhardt, $\mathrm{PhD}^{1}$; Katrin Kuss, $\mathrm{MSc}^{1}$; Annette Becker, MD, $\mathrm{MPH}^{1}$; \\ Heinz-Dieter Basler, $\mathrm{PhD}^{2}$; Jeroen de Jong, $\mathrm{PhD}^{3}$; Brigitta Flatau, $\mathrm{MSc}^{4}$; \\ Marjan Laekeman, $\mathrm{MSc}^{5}$; Peter Mattenklodt, $\mathrm{MSc}^{6}$; Matthias Schuler, $\mathrm{MD}^{7}$; \\ Johan Vlaeyen, $\mathrm{PhD}^{8,9}$; Sabine Quint, $\mathrm{PhD}^{2}$
}

\begin{abstract}
Background and Purpose: Fear-avoidance beliefs in older adults with chronic low back pain (CLBP) can lead to disability. Graded exposure-based active physical therapy could be an option to enhance physical ability in older patients with CLBP. The purpose of this study was to develop a standardized graded exposure treatment according to the fear-avoidance model of musculoskeletal pain for older patients with CLBP and to examine its effectiveness and feasibility in the German health care system.

Methods: The study represents a phase I/phase II trial of a complex intervention. Taking a first step into the hierarchy of growing empirical evidence, a prospective 1-factor observational study was conducted with repeated measurements 1 week before and within 2 weeks after the intervention. Three physical therapists, who completed an introductory workshop, provided the treatment in the form of individual therapies. Sixteen participants 65 years or older with CLBP and perceived physical limitations were recruited. Four patient-reported outcome measures and semistructured interviews were conducted. The primary outcome was physical ability measured with the Hanover Functional Ability Questionnaire. Secondary outcomes were the numerical pain rating scale, and an agespecific and adapted 11 -item short-form of the Patient Anxiety
\end{abstract}

${ }^{1}$ Department of General Practice/Family Medicine, PhilippsUniversity Marburg, Marburg, Germany.

${ }^{2}$ Department of Medical Psychology, Philipps-University Marburg, Marburg, Germany.

${ }^{3}$ Department of Rehabilitation, University Hospital Maastricht/Maastricht University, Maastricht, the Netherlands. 4 "medi train"-Center for Health, Sports Therapy and Physical Therapy, Erlangen, Germany.

${ }^{5}$ Department Nursing Science, Faculty of Health, Witten/ Herdecke University, Witten, Germany.

${ }^{6}$ Interdisciplinary Pain Center, University Hospital Erlangen, Erlangen, Germany.

${ }^{7}$ Diakonissenkrankenhaus Mannheim, Clinic for Geriatrics, Mannheim, Germany.

${ }^{8}$ Department of Clinical Psychological Science, Maastricht University, Maastricht, the Netherlands.

${ }^{9}$ Research Group on Health Psychology, KU Leuven, Leuven, Belgium.

Several parts of this work have been presented on German Congresses in shortened form: German Pain Congress;
Symptom Scale, the KVS-D 65+, which quantified catastrophizing and avoidance beliefs. Fear of falling was measured with the Falls Efficacy Scale-International. For the analysis Wilcoxon signed-rank test for paired samples and an $\alpha$ level of .05 were chosen. For the qualitative evaluation, semistructured interviews were conducted with the patients and physical therapists explored indicators of feasibility such as demands, acceptability, satisfaction, adaptation needs, and implementation. For content analysis, codes were primarily derived deductively and complemented by inductively derived new themes.

Results: A significant increase in physical ability after the treatment was observed with an effect size (ES) of 0.95 $(P=.008)$. With regard to secondary outcomes, there was a statistically significant decrease in pain intensity $(P=.029)$ and a reduction in catastrophizing ( $E S=0.91 ; P=.021)$ and avoidance beliefs ( $E S=1.37 ; P=.001$ ). The interviews revealed good acceptance and satisfaction of the treatment by the patients and physical therapists.

Conclusion: On the whole, the treatment appears effective and feasible. Apart from the benefits achieved by the participants, the study provides a basis for designing future studies at a higher level of evidence.

Congress of the German College of General Practitioners and Family Physicians; Congress of the German Geriatric Society; Congress of the German Society of Psychologists, ALPHA Summer-Symposium.

Funds for the study were granted by the German Research Society (DFG) (grant no. BE 3996/2-1). The DFG had no influence on any content in this project. Dr Vlaeyen was supported by the Odysseus Grant "The Psychology of Pain and Disability Research Program" funded by the Research Foundation, Flanders, Belgium (FWO Vlaanderen, Belgium).

The authors declare no conflicts of interest.

Address correspondence to: Katrin Kuss, MSc, Department of General Practice/Family Medicine, Philipps-University Marburg, Karl-von-Frisch-Strasse 4, 35043 Marburg, Germany (kuss@staff.uni-marburg.de).

Robert Wellmon was the Decision Editor.

Copyright (C) 2017 Academy of Geriatric Physical Therapy, APTA.

DOI: 10.1519/JPT.0000000000000083 
Key Words: chronic pain, fear-avoidance beliefs, graded exposure, older adults, physiotherapy

\section{(J Geriatr Phys Ther 2017;40:51-59.)}

\section{INTRODUCTION}

Chronic low back pain (CLBP) is a common problem in older adults, leading to functional impairment and painrelated disability. ${ }^{1,2}$ Recent epidemiological studies suggest a prevalence of about $30 \%$ for CLBP in this population. ${ }^{3,4}$ Physical and psychosocial disability due to chronic pain is related to social restrictions and loss of function for activities of daily living. ${ }^{5,6} \mathrm{~A}$ recent study from the United States corroborated the interference of pain in the physical capacity of older adults. ${ }^{7}$ Despite the interference of pain, treatment often seems inadequate. ${ }^{8}$

International guidelines concerning chronic pain in older people recommend nonpharmacologic therapies both to avoid problems with multiple medications and to enhance functional capacity and well-being. ${ }^{9,10}$ The guidelines underscore the importance of treatments promoting physical activity. Recently, the MOBILIZE Boston Study demonstrated the importance of physical exercise in older adults for maintaining health. ${ }^{11}$ However, older adults experiencing pain often restrict their physical activity. ${ }^{12}$ Therefore, approaches promoting physical activity, including physiotherapy, have to be sufficiently adapted to the needs of this age group, such as the challenges due to comorbidities, functional limitations, strategically restricted activity, or unfavorable attitudes and beliefs regarding participation in active physical therapy modalities. ${ }^{12}$

People with chronic pain often experience fear of pain or reinjury, as well as associated avoidance behaviors, both of which are well-known risk factors for the emergence of disability. ${ }^{13,14}$ This also pertains to older adults, ${ }^{15-17}$ in whom fear of falling represents a further source of avoidance. ${ }^{18}$ On the basis of the fear-avoidance model of chronic pain, Vlaeyen et $\mathrm{al}^{19-21}$ used a series of single case studies to introduce a treatment approach called "graded exposure in vivo" to treat pain-related fear in patients with chronic pain. The treatment approach described in the literature starts with the identification and building of a hierarchy of movements eliciting fear and avoidance, as well as the identification of related dysfunctional beliefs related to fear of reinjury or pain aggravation. The subsequent treatment steps consist of an initial patient education to disprove misconceptions, followed by gradual exposure in vivo to feared movements until patients feel confident in performing the movements without any support.

The approach described by the working group of Vlaeyen et al has afterward also been incorporated into treatments use by physical therapists for patients experiencing chronic pain, with the aim to return them to activities of daily living. Macedo et $\mathrm{al}^{22}$ and Bailey et $\mathrm{al}^{23}$ reviewed randomized controlled trials relying on graded exposure and found encouraging results. Graded exposure was shown to be effective in reducing fear of pain, pain-related catastrophizing, pain intensity, and disability. ${ }^{24}$ However, there have been no studies on an exposure-based therapy for CLBP, especially in older adults.

The aim of the present study was to test a cognitivebehavioral exposure-based physical therapy program for older patients experiencing CLBP in a primary care setting. "Exposure-based" means the treatment is based on the principles of graded exposure but administered only by a trained physical therapist instead of being paired with a psychologist as is otherwise customary. The present study represents a phase I/phase II trial of a complex intervention using quantitative and qualitative methods to examine the feasibility, acceptance, and potential effectiveness via a pilot study. ${ }^{25}$

\section{METHODS}

\section{Pilot Study Design}

The pilot study represents a prospective, 1-factor observational study with repeated measurements. The trial aimed both to give a first impression of effectiveness and to demonstrate the feasibility of implementing the program in the target population of older adults and outpatient physical therapists. Quantitative measurements took place 1 week before and 2 weeks after the intervention. Qualitative semistructured face-to-face interviews were conducted within 2 to 4 weeks after the individual completed the treatment. Consequently, quantitative and qualitative data are subject to the analysis.

\section{Participants}

Three experienced physical therapists (10-20 years of practice) were recruited voluntarily from an outpatient therapy center to be trained by the study team to deliver the graded exposure treatment. Patients were recruited by general medical practitioners from the department's research network. Potential participants were screened by their physician for study enrollment based on the inclusion and exclusion criteria. Before invitation to the initial assessment, patients were further evaluated for inclusion by the research team over the telephone. Study participants received financial compensation both for travel and parking costs and for time spent with the study procedures (therapies, assessment). Patients were eligible for inclusion if they were at least 65 years old, experienced chronic nonspecific low back pain for at least 3 months as diagnosed by a general practitioner, and if they perceived limitations in daily functions. Patients had to be able to walk, if necessary with a walking aid. Exclusion criteria were "red flag pathologies" such as tumor, fracture, or infection, ${ }^{26}$ severe psychological disorders, or severe mental or cognitive impairment, whereas other comorbidities were tolerated. To explore susceptibility for treatment, patients with different levels of fear of pain and fear of falling were included. 
The calculation of the sample size was based on the expectation of a large treatment effect, a power of $80 \%$, a significance level of $5 \%$, and an estimated correlation between the 2 subsequent measurements of $r=0.4$. As a consequence, 13 participants were needed to test the principal assumption about a significant increase in functional capacity. ${ }^{27}$ However, this number was increased to 16 participants in order to make up for possible attrition.

\section{Therapeutic Concept}

A standardized treatment manual was developed on the basis of the procedure "exposure in vivo", coined by Vlaeyen. ${ }^{28}$ The aim was to adapt this cognitive-behavioral concept to the needs, resources, and life goals of older adults experiencing CLBP. Unlike the Vlaeyen study, this study focused on an older population and took place in a primary care setting. To lower the motivational threshold for the patients, and to facilitate subsequent implementation into the German health care system, patients were treated not by psychotherapists but by physical therapists with previous psychological training. Further adaptation referred to age-related comorbidities and fear of falling. ${ }^{29,30}$

A previously conducted systematic review was included to identify beneficial modalities and factors to support activity promotion in this targeted older adult group. ${ }^{31}$ Results of the review and the treatment manual drafts created by the study team were presented to a panel of international experts from psychology, geriatric medicine, general practice, and physiotherapy to check both on the adaptation of the graded exposure approach and on agerelated adaptation needs. The panel discussed and helped shape the program configuration, the treatment manual, study design and discussed and interpreted the results. Communication was facilitated by 2 general meetings and subsequent feedback via the Internet. In addition, the first meeting featured a 1-day workshop on "exposure in vivo" offered by J. Vlaeyen and J. de Jong.

The final program consists of 12 sessions of 45 -minutes over a 9-week period. The first 3 weeks featured 2 sessions each week; the final 6 weeks featured only 1 session per week. The individually delivered sessions focused on different treatment aspects. Key components were as follows: determination of functional goals (session 1), establishment of a fear hierarchy (session 2), patient education (sessions 2-4), graded exposure to activities causing fear (from session 3 to 11), and transfer into everyday life and reevaluation of the fear hierarchy (sessions 11 and 12) (Table 1).

The establishment and reevaluation of the patient's fear hierarchy were done using the Photograph Series of Daily Activities-German version-for the Elderly (PHODAG-ELD), which consists of 50 photographs representing frequently performed daily activities such as vacuum cleaning, climbing stairs, or putting on socks. ${ }^{15,32}$ The patients were instructed to observe each photograph carefully, to imagine performing the same movement, and to identify the extent that the movement shown would be harmful to their back. The participants then rated the depicted activity on a "harmfulness scale" ranging from 0 (not harmful at all) to 10 (extremely harmful). The psychometric properties of the PHODA-G-ELD are good (internal consistency Cronbach $\alpha=0.97$, retest reliability after 4 weeks $r_{\mathrm{tt}}=$ 0.63). ${ }^{32}$ Construct validity is corroborated by substantial correlations of the instrument with pain and disability. ${ }^{15,32}$

The brief educational sessions included information about differences between acute and chronic pain, the relationship between chronic pain and regular activity, and the role of pain-related fear, avoided activities, and pain memory. Since fear of falling and fear of pain are potential reasons for avoidance, ${ }^{30}$ they were integrated into the educational sessions. At the beginning of the active treatment phase, the physical therapist addressed those activities associated with a medium amount of fear on the PHODA-GELD and then gradually progressed to those with a higher rating. Each practice of activity causing fear was carefully introduced by the physical therapist. Both before and after the performance of the activity, patients rated the level and reason of fear and their level of confidence in the ability to perform this activity in the future.

Table 1. Structure of the Graded Exposure Program

\begin{tabular}{|c|c|c|}
\hline Sessions 1-3 & Sessions 3-11 & Sessions 11-12 \\
\hline $\begin{array}{l}\text { Assessment: pain, fear of falling, physical } \\
\text { examination }\end{array}$ & $\begin{array}{l}\text { Practice of graded exposure to feared activities as } \\
\text { identified by the PHODA: }\end{array}$ & Transfer into everyday life \\
\hline $\begin{array}{l}\text { Establishment of a fear hierarchy } \\
\text { (PHODA-G-ELD) }\end{array}$ & \multirow{3}{*}{$\begin{array}{l}\text { 1. Determination of today's activity } \\
\text { 2. Rating the probability of the feared sensation } \\
\text { 3. Physical practice of the feared activity (as } \\
\text { depicted in the PHODA) until fears decreased } \\
\text { significantly } \\
\text { 4. Rerating of the feared sensation and of being } \\
\text { confident in ability to practice the activity alone }\end{array}$} & Discuss prevention of flare-ups \\
\hline Determination of functional goals (GAS) & & Reevaluation of functional goals (GAS) \\
\hline Patient education & & $\begin{array}{l}\text { Reevaluation of the fear hierarchy and } \\
\text { emphasizing improvements in the selected } \\
\text { activities }\end{array}$ \\
\hline
\end{tabular}


In the first session, each patient chose 2 individual treatment goals using the goal attainment scale (GAS). ${ }^{33,34}$ In case there was a marked fear of falling, reduction of this fear may also be incorporated into the list of goals. At the end of the treatment program, in the process of transferring the learned behavior into everyday life, patients learned to deal with perceived obstacles and new fears that may arise. Finally, the PHODA-G-ELD measurement was repeated to provide feedback for both the patient and the physical therapist.

\section{Study Procedure}

A psychologist (C.L.) and a psychotherapist (S.Q.) worked together to offer a 10-hour training session about the exposure-based treatment to the physical therapists. The training comprised the following topics: working with a standardized manual under study conditions; the biopsychosocial model of illness, including the fear-avoidance model; the particularities of pain in older adults; the practice of building the fear hierarchy; imparting information in educational sessions; and the application of the exposurebased treatment with trial therapy sessions.

The patients were recruited by primary care physicians and subsequently referred by the study team for treatment to 1 of the 3 physical therapists. Treatments took place at the rehabilitation center. One week before and within 2 weeks after completion of the treatment, each patient visited the study center to complete the standardized selfreport measures of functional capacity (primary outcome) and catastrophizing and avoidance beliefs, pain intensity, and fear of falling (secondary outcomes). In addition, all patients and physical therapists participated in individual semistructured face-to-face interviews at the study center within 2 to 4 weeks after treatment.

While conducting the treatment, the 3 physical therapists taped 2 sessions for review by the psychologist and the psychotherapist to check on adherence to the treatment regimen. All videos were reviewed by the psychologist and the psychotherapist, who offered the training for the physical therapists. Besides 2 group supervision meetings to give feedback to the physical therapists, they were free to clarify any questions by phone or e-mail at any time during the treatment process.

\section{Outcome Measures}

Functional capacity was designated as primary outcome because it appears to be an indicator of an autonomous life and relevant for community-dwelling older adults. As the suspected mechanisms of the procedure involve reduction of catastrophizing and avoidance beliefs and fear of falling, those were chosen, together with pain intensity, for secondary outcomes. Functional capacity was measured by the Hanover Functional Ability Questionnaire (HFAQ), a frequently used instrument for the assessment of back pain-related disability in German-speaking regions, and a scale with good psychometric properties. The values measured are transferred into percent scores that indicate the functional state of the individual. The minimal clinically relevant difference is $12 \%$; scores below $60 \%$ are assumed to depict disability. ${ }^{35}$ A comparison of the HFAQ with the Roland and Morris Scale in a German population demonstrated good internal consistency of both scales $(r>$ 0.85 ), a retest reliability of 0.91 , and an intercorrelation of both scales of $0.75 .{ }^{36}$ Correlations with further disability measures indicate a concurrent validity of the HFAQ that is equivalent to the Roland and Morris Scale. The HFAQ was chosen, which is especially advantageous for older adults because it only consists of 12 items, without losing psychometric quality compared with the Roland and Morris Scale.

For secondary outcomes, pain intensity was rated on an 11-point numerical rating scale (NRS), where $0=$ no pain and $10=$ worst pain, using the approach recommended by von Korff et al. ${ }^{37}$ The authors suggest an average value of the worst, the current, and the average pain intensity over the past 3 months. In this article, the average value of these 3 ratings within the last week before the initial and final assessments is reported, respectively. Internal consistency of the subscales is moderate to good (Cronbach $\alpha=0.68$ 0.88)..$^{38}$

Catastrophizing and avoidance beliefs were measured using an age-specific and adapted 11-item short-form of the Patient Anxiety Symptom Scale, ${ }^{39}$ the KVS-D 65+, which is validated in the German language. The KVS-D 65+ consists of 2 subscales, Catastrophizing and Avoidance. Patients report on 6-point Likert scales ranging from 0 (never) to 5 (always) how frequently they have the perception of pain-related fearful thoughts or how often they perform pain-avoiding behavioral responses. A mean score of each subscale is created by dividing the sum of the category by its number of items. The questionnaire is reliable (retest $r=0.67-0.70$ ) and valid (Cronbach $\alpha=0.87-0.92$ for the total scale and from 0.71 to 0.89 for the subscales Catastrophizing and Avoidance)..$^{40}$

Fear of falling was measured with the Falls Efficacy Scale-International ${ }^{41}$ in its validated German version. ${ }^{42}$ The scale comprises 16 items that relate to different advanced activities of daily living. For each item, participants are asked to state how concerned they are about the possibility of falling. Scores range from a minimum of 16 (low fear of falling) to a maximum of 64 . The scale shows high validity $(\alpha=.96)$ and retest-reliability $(r=0.96) .{ }^{41}$ Patient satisfaction was measured with an additional question on an 11-point NRS, with scores ranging from 0 (not at all) to 10 (completely satisfied). For patient demographics, age, sex, and years of education were collected in a case report form. Finally, at baseline, there was a screening for depression utilizing the 15 -item Geriatric Depression Scale. ${ }^{43,44}$ 
Scores 5 points or less reflect no depression. The scale is reliable (split-half reliability $r=0.90)$ and valid $(\alpha=.91)$ in discriminating patients with a depression disorder.

For the face-to-face interviews of patients and physical therapists, the study team developed semistructured interview guides for both groups, examining key themes related to feasibility. ${ }^{45}$ Topics covered were demands, acceptability (appropriateness, comprehensibility, satisfaction, goal attainment, and individual changes), adaptation needs (program, treatment manuals, therapists' training and supervision), and practicality and implementation within the primary care setting. Patient interviews were conducted within 2 weeks by 2 authors (C.L., K.K.). For reasons of practicality, patients' answers were written down verbatim during the interviews. Therapist interviews were conducted by 1 author (C.L.), audiotaped, later transcribed verbatim, and then analyzed using MAXQDA 11 (2010; VERBI Software Consult, Sozialforschung GmbH, Berlin, Germany).

\section{Quantitative and Qualitative Analyses of Data}

All quantitative data analyses were conducted using the IBM SPSS Statistics for Windows, version 19.0 (released 2010; IBM Corp, Armonk, New York). To test the assumptions, the Wilcoxon signed-rank test for paired samples was used. This was due to the small number of participants and not normally distribution of data, respectively. The $\alpha$ level for statistical significance was set .05. For analysis of qualitative data, a content analysis was initially performed by one interviewer (C.L.) and trustworthiness verified independently by a second (K.K.); discrepancies were resolved by consensus. The coding tree was deductively derived from the interview guide and supplemented by inductively derived new themes.

The study was approved by the local ethics committee of the Philipps-University Marburg (ethical approval from May 14, 2010; reference no. 66/10) and is in accordance with the Declaration of Helsinki 1975, revised Hong Kong 1989. Informed consent was obtained from all patients and the 3 therapists.

\section{RESULTS}

\section{Quantitative Results}

General practitioners recruited patients during their regular consultations between November 2012 and April 2013. Patient demographics at baseline are described in Table 2. All participants completed the intervention and participated in all assessments without any missing data. No serious adverse events were observed in any of the participants.

Table 3 depicts the individual scores of the patients in all outcome variables at baseline and 2 weeks posttreatment. On average, depression scores are low, except for 1 patient. All but 3 patients $(81 \%)$ improved in functional ability, and $11(69 \%)$ of the 16 participants had clinical meaningful
Table 2. Patient Demographics

\begin{tabular}{|l|c|}
\hline Characteristic & All Participants ( $=16)$ \\
\hline Age, mean (SD, range), y & $72.6(4.7,65-80)$ \\
\hline Sex: Female, $\mathrm{n}(\%)$ & $10(62.5)$ \\
\hline Education $\leq 10 \mathrm{y}, \mathrm{n}(\%)$ & $14(87.5)$ \\
\hline $\begin{array}{l}\text { Depression, mean (SD), Geriatric } \\
\text { Depression Scale }\end{array}$ & $2.8(3.2)$ \\
\hline Abbreviation: SD, standard deviation. & \\
\hline
\end{tabular}

results. Regarding group changes, Table 4 shows that the primary outcome functional ability improved by an average of $16.9 \%$, a change that is statistically significant and represents a large effect size. With regard to the secondary outcomes, there was a statistically significant decrease in catastrophizing and avoidance, with a large effect size in the reduction of avoidance. In addition, there was a statistically significant decrease in pain intensity; fear of falling did not change significantly.

\section{Qualitative Results}

Reasons for avoidance behavior, documented by the physical therapists before and after the performance of each activity causing fear in the sessions, were fear of pain (mentioned in $37 \%$ of the cases), fear of falling/dizziness $(24 \%)$, fear of injury/harmfulness $(18 \%)$, and nonspecific exacerbation/loss of strength $(21 \%)$.

In the interviews, 14 of the 16 patients stated they were very satisfied with the outcome. They reported being more active despite their pain and experiencing less fear. Several patients reported that they had continued setting new activity-based goals. Disappointment in 2 patients was due to divergent expectations ("I thought it would be something new from medicine," P10; "I rather expected manual therapy," P15). On the whole, patients accepted the duration and frequency of the sessions and indicated the series of age-specific photographs as being very useful. Half of them, however, suggested incorporating more or different photographs into the PHODA-G-ELD.

All 3 physical therapists emphasized the importance of the workshop, especially the practice therapy sessions, prior to the trial. Although the preparation was rated as sufficient, there was a desire to augment it with training on communication skills, especially with regard to both resistance and negative perceptions. In addition, therapists expressed the desire for more frequent supervision. They rated the manual as being essential and the photographs as very useful to confront the patients with feared and avoided behavior. They felt themselves challenged by a distinction between irrational fear and functionally justified fear. On the whole, however, they believed that the treatment could be incorporated into physiotherapeutic practice. Finally, the therapists suggested some changes to the program. They would have liked photographs with different seasonal activities and 
Table 3. Individual Outcomes of Patients at Baseline and 2 Weeks Posttreatment

\begin{tabular}{|c|c|c|c|c|c|c|c|c|c|c|c|c|c|c|}
\hline \multirow[t]{2}{*}{ Patient } & \multirow[t]{2}{*}{ Sex } & \multirow[t]{2}{*}{$\begin{array}{l}\text { Age, } \\
y\end{array}$} & \multirow[t]{2}{*}{$\begin{array}{l}\text { Depression } \\
\text { (GDS) (0-15) }\end{array}$} & \multicolumn{3}{|c|}{$\begin{array}{l}\text { Functional Ability \% (HFAQ) } \\
\text { (Primary Outcome) }\end{array}$} & \multicolumn{2}{|c|}{$\begin{array}{l}\text { Pain Intensity } \\
\text { (NRS) (0-10) }\end{array}$} & \multicolumn{2}{|c|}{$\begin{array}{l}\text { Catastrophizing } \\
\text { (KVS-D 65+) (0-5) }\end{array}$} & \multicolumn{2}{|c|}{$\begin{array}{l}\text { Avoidance Beliefs } \\
\text { (KVS-D 65+) (0-5) }\end{array}$} & \multicolumn{2}{|c|}{$\begin{array}{l}\text { Fear of Falls } \\
\text { (FES-I) }(16-64)\end{array}$} \\
\hline & & & & Pre & Post & Difference & Pre & Post & Pre & Post & Pre & Post & Pre & Post \\
\hline 1 & Male & 78 & 3 & 62.5 & 75.0 & +12.5 & 5.7 & 3.3 & 3.2 & 0.7 & 3.6 & 1.2 & 29 & 24 \\
\hline 2 & Female & 78 & 0 & 41.7 & 70.8 & +29.1 & 6.0 & 5.0 & 1.0 & 2.0 & 2.8 & 1.6 & 23 & 25 \\
\hline 3 & Female & 78 & 4 & 20.8 & 37.5 & +16.7 & 7.0 & 7.0 & 4.0 & 1.7 & 4.6 & 1.8 & 49 & 29 \\
\hline 4 & Male & 80 & 2 & 70.8 & 100 & +29.2 & 7.0 & 4.3 & 3.3 & 0.8 & 4.6 & 0.4 & 18 & 17 \\
\hline 5 & Female & 67 & 4 & 62.5 & 83.3 & +20.8 & 5.7 & 3.0 & 2.5 & 1.3 & 1.0 & 0.4 & 22 & 20 \\
\hline 6 & Female & 78 & 0 & 37.5 & 95.8 & +58.3 & 10.0 & 4.0 & 1.7 & 0.7 & 2.4 & 0.0 & 36 & 18 \\
\hline 7 & Female & 69 & 0 & 75.0 & 83.3 & +8.3 & 4.7 & 5.3 & 0.7 & 1.8 & 0.8 & 1.4 & 22 & 21 \\
\hline 8 & Male & 68 & 3 & 75.0 & 87.5 & +12.5 & 6.3 & 5.7 & 0.7 & 0.3 & 2.8 & 1.4 & 22 & 18 \\
\hline 9 & Female & 72 & 0 & 41.7 & 75.0 & +33.3 & 6.0 & 6.0 & 2.5 & 1.0 & 2.6 & 0.6 & 23 & 20 \\
\hline 10 & Female & 72 & 4 & 62.5 & 50.0 & -12.5 & 8.3 & 7.7 & 2.2 & 2.2 & 4.0 & 3.6 & 20 & 21 \\
\hline 11 & Male & 65 & 13 & 66.6 & 41.7 & -24.9 & 7.3 & 9.0 & 1.7 & 2.7 & 3.4 & 1.0 & 29 & 51 \\
\hline 12 & Female & 72 & 2 & 29.2 & 70.8 & +41.6 & 6.0 & 4.3 & 2.0 & 0.0 & 1.6 & 0.2 & 43 & 30 \\
\hline 13 & Male & 75 & 5 & 62.5 & 70.8 & +8.3 & 7.0 & 6.3 & 2.7 & 1.3 & 3.4 & 1.6 & 23 & 26 \\
\hline 14 & Male & 72 & 3 & 41.7 & 66.7 & +25.0 & 6.9 & 7.0 & 3.5 & 3.2 & 3.2 & 3.2 & 18 & 23 \\
\hline 15 & Female & 71 & 0 & 66.7 & 62.5 & -4.2 & 5.0 & 4.3 & 1.3 & 0.8 & 4.2 & 2.4 & 22 & 23 \\
\hline 16 & Female & 67 & 2 & 79.2 & 95.8 & +16.6 & 4.3 & 2.0 & 2.3 & 1.3 & 3.0 & 2.0 & 24 & 22 \\
\hline
\end{tabular}

proposed better incorporating the prevention of falls. They felt that the standardized program does not allow for dayto-day changes in physical restrictions of the patients. With regard to the evaluation, they suggested a functional test that allowed better observation of the actual behavior.

\section{DISCUSSION}

The purpose of the present study was to test the feasibility and preliminary effectiveness of a cognitive-behavioral graded exposure treatment delivered by physical therapists in a primary care setting. In contrast to traditional physical therapy treatment approaches where mostly a combination of passive techniques and muscle strengthening or aerobic conditioning exercises are applied, the graded exposure approach directly confronts patients with specific feared movements and related misconceptions. A convenience sample of 16 older patients with chronic nonspecific back pain participated in the study. All 16 finished the treatment and provided a complete set of data. This clearly shows the high motivation of the sample and may be a prerequisite for a beneficial outcome.

Table 4. Changes in Primary and Secondary Outcomes

\begin{tabular}{|c|c|c|c|c|c|}
\hline Variable & Pretreatment & Posttreatment & $Z$ & $P$ & Effect Size \\
\hline \multicolumn{6}{|l|}{ Primary outcome } \\
\hline Functional ability (HFAQ), mean (SD) & $56.0(17.9)$ & $72.9(18.5)$ & -2.67 & .01 & 0.95 \\
\hline \multicolumn{6}{|l|}{ Secondary outcomes } \\
\hline Catastrophizing (KVS-D 65+), mean (SD) & $2.2(1.0)$ & $1.4(0.9)$ & -2.31 & .02 & 0.91 \\
\hline Avoidance (KVS-D 65+), mean (SD) & $3.0(1.2)$ & $1.4(1.0)$ & -3.27 & .00 & 1.37 \\
\hline Pain intensity (NRS), median (interquartile range) & $6.0(1.3)$ & $5.2(2.8)$ & -2.18 & .03 & $\ldots$ \\
\hline Fear of falls (FES-I), mean (SD) & $25.9(9.0)$ & $24.3(8.1)$ & -1.09 & .278 & 0.18 \\
\hline
\end{tabular}


Functional ability as the primary outcome increased considerably with a large effect size. This may be due to a decline of negative perceptions, such as catastrophizing and avoidance behavior. As avoidance behavior is part of the treatment focus, the large effect size in this variable also suggests training effectiveness. Average pain intensity within the last week also shows improvement in two-thirds of the patients. Falls efficacy, however, remained constant throughout the treatment. The mean of this variable was admittedly low before treatment and therefore is less likely to change.

The results of this study corroborate the findings of Beissner et al, ${ }^{46}$ who examined the feasibility of a combined exercise and cognitive-behavioral group program for older adults with CLBP. The authors found an average improvement in disability of $22 \%$. Mailloux et $\mathrm{al}^{47}$ and Weiner et $\mathrm{al}^{48}$ also used an activity-promoting treatment in groups of older patients with back pain. They, too, found an improvement in disability between $10 \%$ and $13 \%$, albeit in the study of Weiner et al only in combination with transcutaneous electrical nerve stimulation. The present results exceed those of a previous study we performed with physiotherapeutic interventions in a group setting. ${ }^{49}$ Neither participants in the control group, who received additional placebo ultrasound, nor participants in the intervention group, who received additional motivational counseling by the physical therapists to promote behavioral changes in activity, attained clinically meaningful improvement of functional ability. The superiority of the actual results could be due to the individualized approach that addresses fear avoidance, previously shown to be a risk factor for disability. ${ }^{15}$

The individual results show that 3 patients (patients 10, 11, and 15) did not improve with regard to functional ability. Patient 10 had received a diagnosis of advanced osteoporosis and felt herself strained by caring for her husband who was disabled. Lack of success in patient 11 is possibly due to a high score in depression, as measured by the Geriatric Depression Scale, and a strong belief in the biomechanical model of disease, as perceived by the physical therapist during treatment. The reason for a slightly worse functional ability in patient 15 may be lack of adherence caused by different treatment expectations (as observed by the physical therapist). In general, the treatment showed beneficial effects in nearly all of the patients and seems to be appropriate for functionally impaired participants open to a biopsychosocial model of pain. The supervision videos revealed that the presence of the physical therapist during exposure to previously avoided activities seemed to be essential in prompting new behavior.

The interviews show that the physical therapists were motivated and enabled to integrate cognitive-behavioral exposure-based techniques into their work. This is in accordance with findings of Archer et $\mathrm{al}^{50}{ }^{50} \mathrm{Bach}$ et $\mathrm{al},{ }^{51}$ and George et al, ${ }^{52}$ with different cognitive-behavioral techniques in different health care systems. In addition to the topics of the initial workshop, the therapists suggested incorporating teaching communication skills to be better enabled to discern which patients need additional psychotherapy.

Moreover, physical therapists felt the challenge to discriminate between the avoidance of activities that may be due to fear and those due to functional limitation. Older people with chronic back pain often have multiple pain sites and comorbidities that need to be addressed. ${ }^{7}$ Life goals are different from those of younger people, and activity restriction is often a result of paradoxical beliefs. ${ }^{12,53}$ In the patient group presented here, fear of pain was the most frequent concern whereas fear of falling was the dominant fear in a group studied by Hadjistavropoulos et al. ${ }^{30}$ Therapists must be able to determine the reasons for avoidance behavior. A more explicit incorporation of falls prevention could be added by drawing from established treatment programs.

A treatment manual contributed to facilitating the work of the physical therapists. An advantage of the present study was a standardized treatment procedure and the adherence to the manual that was reinforced by supervision and video recordings. Several limitations to the study exist. The convenience sample was recruited by general practitioners on the basis of first-come first-served, and there are no data on the refusal rate. Possibly, participants were highly motivated, an assumption also corroborated by the high rate of adherence and the complete lack of missing data. For the present, this article only reports short-term effects of the treatment. Moreover, the results rely on self-report data that should be complemented by functional tests and behavioral observation in the future. A major limitation of the study is its quasi-experimental design, as no control condition was available. Many authors conclude that there is no "one-size-fits-all" strategy for patients with chronic pain looking to achieve substantial effects in disability or quality of life. Future studies have to investigate which patient groups will gain most from a physiotherapeutic approach based on psychological principles.

Nonetheless, the study ought to be an important step within the hierarchy of growing evidence about the treatment of fear avoidance in older adults. Given the fact that there are different levels of evidence in the process of research, studies that represent a lower level of evidence are considered to be a requisite of more advanced research. The present study showed that the treatment is feasible in the German health care system and that the collaboration between primary care physicians, physical therapists, and psychologists show beneficial effects. Moreover, knowing the effect size of the treatment may facilitate subsequent power calculations. Randomized controlled studies are cost-intensive and need to be founded on low-cost studies with a less refined methodology. 


\section{CONCLUSION}

Exposure-based treatment applied by physical therapists in collaboration with primary care physicians and psychologists showed promising results with respect to treatment outcomes and feasibility. It seems to be suitable for older patients who have chronic pain with fear-avoidance behavior and are functionally impaired. Apart from the benefits achieved by the participants, the study offers practical guidance for physical therapists and also facilitates further research. On the basis of our data, investigators are encouraged to methodologically design more refined studies.

\section{ACKNOWLEDGMENTS}

The authors thank Tobias Fischer, Sabine Kreuder, and Andreas Tiedemann for their dedicated and reliable performance as physical therapists. The authors also thank Juliette Rautenberg for providing English-language editing, improving the precision and fluency of the manuscript.

\section{REFERENCES}

1. Buchman AS, Shah RC, Leurgans SE, Boyle PA, Wilson RS, Bennett DA. Musculoskeletal pain and incident disability in community-dwelling older adults. Arthritis Care Res. 2010;62(9):1287-1293.

2. Soldato M, Liperoti R, Landi F, et al. Nonmalignant daily pain and risk of disability among older adults in home care in Europe. Pain. 2007;129(3): 304-310.

3. Fejer R, Ruhe A. What is the prevalence of musculoskeletal problems in the elderly population in developed countries? A systematic critical literature review. Chiropr Man Therap. 2012;20(1):31.

4. Cecchi F, Debolini P, Lova RM, et al. Epidemiology of back pain in a representative cohort of Italian persons 65 years of age and older: the InCHIANTI study. Spine. 2006;31(10):1149-1155.

5. Shah RC, Buchman AS, Boyle PA, et al. Musculoskeletal pain is associated with incident mobility disability in community-dwelling elders. J Gerontol A Biol Sci Med Sci. 2010;66(1):82-88.

6. Landi F, Russo A, Liperoti R, et al. Daily pain and functional decline among old-old adults living in the community: results from the iISIRENTE study. $J$ Pain Symptom Manag. 2009;38(3):350-357.

7. Patel KV, Guralnik JM, Dansie EJ, Turk DC. Prevalence and impact of pain among older adults in the United States: findings from the 2011 National Health and Aging Trends Study. Pain. 2013;154(12):2649-2657.

8. Gibson SJ. IASP global year against pain in older persons: highlighting the current status and future perspectives in geriatric pain. Expert Rev Neurother. 2007;7(6):627-635

9. Abdulla A, Adams N, Bone M, et al. Guidance on the management of pain in older people. Age Ageing. 2013;42(suppl 1):i1-i57.

10. AGS Panel on Persistent Pain in Older Persons. The management of persistent pain in older persons. J Am Geriatr Soc. 2002;50(6)(suppl): S205-S224.

11. Stewart C, Leveille SG, Shmerling RH, Samelson EJ, Bean JF, Schofield P. Management of persistent pain in older adults: the MOBILIZE Boston Study. J Am Geriatr Soc. 2012;60(11):2081-2086.

12. Mackichan F, Adamson J, Gooberman-Hill R. "Living within your limits": activity restriction in older people experiencing chronic pain. Age Ageing. 2013;42(6):702-708

13. Zale EL, Lange KL, Fields SA, Ditre JW. The relation between pain-related fear and disability: a meta-analysis. J Pain. 2013;14(10):1019-1030.

14. Leeuw M, Goossens M, Linton S, Crombez G, Boersma K, Vlaeyen J. The fear-avoidance-model of musculoskeletal pain: current state of scientific evidence. J Behav Med. 2007;30(1):77-94.

15. Basler HD, Luckmann J, Wolf U, Quint S. Fear-avoidance beliefs, physical activity, and disability in elderly individuals with chronic low back pain and healthy controls. Clin J Pain. 2008;24(7):604-610.

16. Camacho-Soto A, Sowa GA, Perera S, Weiner DK. Fear avoidance beliefs predict disability in older adults with chronic low back pain. PMR. 2012;4(7):493-497.

17. Sions JM, Hicks GE. Fear-avoidance beliefs are associated with disability in older American adults with low back pain. Phys Ther. 2011;91(4): 525-534.

18. Leonhardt C, Laekeman M. Pain and fear of movement in the elderly. The need for an interdisciplinary approach. [German]. Schmerz. 2010;24(6): 561-568.
19. Vlaeyen JW, de Jong J, Geilen M, Heuts PH, van Breukelen G. Graded exposure in vivo in the treatment of pain-related fear: a replicated singlecase experimental design in four patients with chronic low back pain. Behav Res Ther. 2001;39(2):151-166.

20. Vlaeyen JW, de Jong J, Geilen M, Heuts PH, van Breukelen G. The treatment of fear of movement/(re)injury in chronic low back pain: further evidence on the effectiveness of exposure in vivo. Clin J Pain. 2002; 18(4):251-261.

21. Vlaeyen JW, Crombez G. Fear of movement/(re)injury, avoidance and pain disability in chronic low back pain patients. Man Ther. 1999;4(4): 187-195.

22. Macedo LG, Smeets RJ, Maher CG, Latimer J, McAuley JH. Graded activity and graded exposure for persistent nonspecific low back pain: a systematic review. Phys Ther. 2010;90(6):860-879.

23. Bailey KM, Carleton RN, Vlaeyen JWS, Asmundson GJG. Treatments addressing pain-related fear and anxiety in patients with chronic musculoskeletal pain: a preliminary review. Cogn Behav Ther. 2010;39(1) 46-63.

24. George SZ, Wittmer VT, Fillingim RB, Robinson ME. Comparison of graded exercise and graded exposure clinical outcomes for patients with chronic low back pain. J Orthop Sports Phys Ther. 2010;40(11):694-704.

25. Campbell M, Fitzpatrick R, Haines A, et al. Framework for design and evaluation of complex interventions to improve health. BMJ. 2000;321 (7262):694-696

26. Koes BW, van Tulder M, Lin CC, Macedo LG, McAuley J, Maher C. An updated overview of clinical guidelines for the management of non-specific low back pain in primary care. Eur Spine J. 2010;19(12):2075-2094.

27. Bortz J, Doering N. Research Methods and Evaluation for Human- and Social Scientists [German]. 4th ed. Berlin, Germany: Springer; 2006.

28. Vlaeyen JWS. Pain-Related Fear: Exposure-Based Treatment for Chronic Pain. Seattle, WA: IASP Press; 2012.

29. Delbaere K, Crombez G, Vanderstraeten G, Willems T, Cambier D. Fear related avoidance of activities, falls and physical frailty. A prospective community-based cohort study. Age Ageing. 2004;33(4):368-373.

30. Hadjistavropoulos T, Martin RR, Sharpe D, Lints AC, McCreary DR, Asmundson GJG. A longitudinal investigation of fear of falling, fear of pain, and activity avoidance in community-dwelling older adults. J Aging Health. 2007; 19(6):965-984.

31. Kuss K, Becker A, Quint S, Leonhardt C. Activating therapy modalities in older individuals with chronic non-specific low back pain: a systematic review. Physiotherapy. 2015;101(4):310-318.

32. Quint S, Luckmann J, Wolf U, Basler H. AMIKA: psychometric evaluation of a photo-based scale for the assessment of fear avoidance beliefs in elderly individuals [German]. Schmerz. 2007;21(5):453-461.

33. Rockwood K, Stolee P, Fox RA. Use of goal attainment scaling in measuring clinically important change in the frail elderly. J Clin Epidemiol. 1993;46(10):1113-1118

34. Fairhall N, Sherrington C, Kurrle SE, Lord SR, Lockwood K, Cameron ID. Effect of a multifactorial interdisciplinary intervention on mobility-related disability in frail older people: randomised controlled trial. BMC Med. 2012; 10:120.

35. Kohlmann T, Raspe H. Hannover Functional Questionnaire in ambulatory diagnosis of functional disability caused by backache [German]. Rehabilitation. 1996;35(1):I-VIII.

36. Roese I, Kohlmann T, Raspe H. Measurement of functional capacity in rehabilitation patients with back pain: comparative analysis of standardized questionnaires [German]. Rehabilitation. 1996;35(2):103-108.

37. von Korff M, Ormel J, Keefe F, Dworkin SV. Grading the severity of chronic pain. Pain. 1992;50(2):133-149.

38. Klasen BW, Hallner D, Schaub C, Willburger R, Hasenbring M. Validation and reliability of the German version of the Chronic Pain Grade questionnaire in primary care back pain patients. Psychosoc Med. 2004;1:Doc07.

39. McCracken LM, Dhingra L. A short version of the Pain Anxiety Symptoms Scale (PASS-20): preliminary development and validity. Pain Res Manag. 2002;7(1):45-50

40. Quint S, Raich M, Luckmann J. Evaluation of a two-dimensional scale for the assessment of fear avoidance beliefs in elderly chronic low back pain patients [German]. Schmerz. 2011;25(3):315-321.

41. Yardley L. Development and initial validation of the Falls Efficacy ScaleInternational (FES-I). Age Ageing. 2005;34(6):614-619.

42. Dias N, Kempen GIJM, Todd CJ, et al. The German version of the Falls Efficacy Scale-International Version (FES-I) [German]. Z Gerontol Geriatr. 2006;39(4):297-300.

43. Yesavage J, Brink $T$, Rose $T$, et al. Development and validation of a geriatric depression screening scale: a preliminary report. J Psychiatr Res. 1983;17(1):37-49.

44. Gauggel S, Birkner B. Validity and reliability of a German version of the Geriatric Depression Scale (GDS) [German]. Z Klin Psychol Psychother. 1999;28(1):18-27.

45. Bowen DJ, Kreuter M, Spring B, et al. How we design feasibility studies. Am J Prev Med. 2009;36(5):452-457 
46. Beissner K, Bach E, Murtaugh C, Parker SJ, Trachtenberg M, Reid MC. Implementing a cognitive-behavioral pain self-management program in home health care, part 1: program adaptation. J Geriatr Phys Ther. 2013;36(3): 123-129.

47. Mailloux J, Finno M, Rainville J. Long-term exercise adherence in the elderly with chronic low back pain. Am J Phys Med Rehab. 2006; 85(2): 120-126.

48. Weiner DK, Perera S, Rudy TE, Glick RM, Shenoy S, Delitto A. Efficacy of percutaneous electrical nerve stimulation and therapeutic exercise for older adults with chronic low back pain: a randomized controlled trial. Pain. 2008;140(2):344-357.

49. Basler HD, Bertalanffy H, Quint S, Wilke A, Wolf U. TTM-based counselling in physiotherapy does not contribute to an increase of adherence to activity recommendations in older adults with chronic low back pain-a randomised controlled trial. Eur J Pain. 2007;11(1):31-37.

50. Archer KR, Motzny N, Abraham CM, et al. Cognitive-behavioral-based physical therapy to improve surgical spine outcomes: a case series. Phys Ther. 2013;93(8):1130-1139.

51. Bach E, Beissner K, Murtaugh C, Trachtenberg M, Reid MC. Implementing a cognitive-behavioral pain self-management program in home health care, part 2: feasibility and acceptability cohort study. J Geriatr Phys Ther. 2013;36(3):130-137.

52. George SZ, Zeppieri G. Physical therapy utilization of graded exposure fo patients with low back pain. J Orthop Sports Phys Ther. 2009;39(7):496-505.

53. Crombez G, Eccleston C, Damme S, Vlaeyen J, Karoly P. Fear-avoidance model of chronic pain: the next generation. Clin J Pain. 2012;28(6):475-483 